\title{
Role of Endobronchial Ultrasound in Diagnosis of Mediastinal and Pulmonary Lesions
}

\author{
GAMAL E.A. EL-SAYED, M.D. ${ }^{1}$; MOUSA M. EL-SHAMLY, M.D. ${ }^{\mathbf{2}}$; ABD ALLAH S. AYOB, M.D. ${ }^{2}$; \\ KHALED M. ZAMZAM, M.D. ${ }^{3}$ and SAAD E.H. SALAH ELDIN, M.Sc. ${ }^{4}$ \\ The Departments of Pathology ${ }^{1}$, Chest Diseases ${ }^{2}$, Faculty of Medicine, Al-Azhar University, Military Chest Department, \\ Kobbry Al-Kobba Hospital ${ }^{3}$ and Chest Diseases, El-Abassia Chest Hospital ${ }^{4}$, Cairo
}

\begin{abstract}
Background: Lung cancer is one of the most common tumors worldwide. Now it ranks as the leading cause of cancer related death in the world, both in men and women. Pulmonary lesions detected during screening for lung cancer need to be evaluated further and tissue should be obtained. Technical development in last two decades has made it possible for pulmonologists to do endobronchial ultrasound "EBUS".
\end{abstract}

Aim of Study: The aim of the work is Assessment of the role of endobronchial ultrasound TBNA in diagnosis of mediastinal lesions as accurate rapid less invasive procedure.

Subjects and Methods: This is a Prospective study was conducted on 30 patients presented with chest symptoms (dyspnea, cough, expectoration, chest pain and hemoptysis) diagnosed as mediastinal, hilar and pulmonary lesions as confirmed by CT chest, routine labs and proper history taking and through clinical examination and underwent EBUS-TBNA and the sampled lesion was sent for histopathological examination and reporting at Kobbry Al-Kobba Military Hospital during the period from (November 2015 to October 2016).

Results: The mean age of the patients participating in this study was $44.9 \pm 15.9$ years (ranges $17-73$ ). $56.7 \%$ of them were males while $43.3 \%$ were femles. Radiological finding showed Hilar \& mediastinal lymphadenopathy in $40.0 \%$, mediastinal lymphadenopathy $(6.7 \%)$, hilar lymphadenopathy $(10.0 \%)$, pulmonary lesions $(33.3 \%)$, pulmonary lesions with mediastinal lymphadenopathy $(6.7 \%)$, pulmonary lesions with mediastinal and hilar lymphadenopathy (3.3\%). EBUS findings were 20 patients were having lymph node lesions $(85 \%$ were benign and $15 \%$ were malignant by pathology) and 10 patients were having mass lesions ( $100 \%$ were malignant). No complications were detected only minor hemorrhage in 1 patients $(3.3 \%)$.

Conclusion: Endobronchial ultrasound guided transbronchial fine needle aspiration EBUS-TBNA is the procedure of choice for staging of lung cancers and for the investigation of unexplained mediastinal lymphadenopathy and masses. EBUS guided TBNA is an accurate, cost effective and minimally invasive procedure and if successfully performed, TBNA may spare patients additional, more invasive procedures or surgery.

Correspondence to: Dr. Gamal E.A. El-Sayed, The Department of Pathology, Faculty of Medicine, Al-Azhar University
Key Words: Lung Cancer-EBUS - Pulmonary-Mediastinal lesions.

\section{Introduction}

LUNG cancer is one of the most common tumors worldwide. Now it ranks as the leading cause of cancer related death in the world, both in men and women. The cancer is usually diagnosed in the advanced stages of the disease and screening for the disease has proven difficult. Pulmonary lesions detected during screening for lung cancer need to be evaluated further and tissue should be obtained [1].

Technical development in last two decades has made it possible for pulmonologists to do endobronchial ultrasound "EBUS" [2].

Endobronchial ultrasound (EBUS) is a technique that uses ultrasound along with bronchoscope to visualize airway wall and structures adjacent to it [3].

EBUS has become a hot topic in all major conferences and is becoming an essential bronchoscopic tool. With the recent introduction of dedicated ultrasonic bronchoscope with real time guidance for needle aspiration there is widespread acceptance of this novel method leading to a 'new dawn for respiratory physician' [4].

EBUS-guided transbronchial needle aspiration (TBNA) has higher diagnostic yield than conventional TBNA in all lymph node stations except subcarinal lymph nodes in determining the lymph node involvement in non-small cell lung carcinoma "NSCLC". Its ability to precisely visualize the airway wall invasion helps to categorize the tumor (T) component of staging and surgical resection planning. TBNA can be combined with endoscopic ultrasound-guided fine-needle aspiration to near complete sampling of mediastinum using a single 
endobronchial ultrasound bronchoscope. It can also be used to restage the lung cancer in mediastinum [5].

EBUS can visualize and allow physicians to sample and diagnose various mediastinal abnormalities [6], including sarcoidosis [7] and mediastinal lymphoma [8]. It can characterize the intraparenchymal and endobronchial lesions and help to determine the likelihood of malignancy based on appearance. EBUS-TBNA can visualize and allow sampling of pulmonary nodules that are not visualized by fluoroscopy and may avert the need for surgical procedures [9]. RP-EBUS is relatively accurate tool in the investigation of peripheral pulmonary lesions [10]

\section{Subjects and Methods}

This is a Prospective study that was carried out in Outpatient Clinics of Al-Abasia Chest Hospital in collaboration with Chest Diseases, Pathology Departments, Faculty of Medicine, Al-Azhar University, and Military Chest Hospital in Kobbry Alkobba Hospital during the period from Nov. 2015 to Oct. 2016.

Before the start of the study, permission was obtained from Ethical Committee in the Faculty of Medicine, Al-Azhar University. Also Informed written consents from patients included in the study was obtained.

Subjects: A total number of 30 patients, presented with chest symptoms (dyspnea, cough, expectoration, chest pain and hemoptysis) diagnosed as mediastinal, hilar and pulmonary lesions as confirmed by CT chest, routine labs and proper history taking and through clinical examination and underwent EBUS-TBNA and the sampled lesion was sent for histopathological examination and reporting at Military Chest Hospital in Kobbry Al-Kobba Hospital.

Inclusion criteria: All patients diagnosed with mediastinal, hilar and pulmonary lesions were assessed to be fit for EBUS-TBNA was included in our study.

Exclusion criteria: Any patient unfit for EBUSTBNA (uncooperative, respiratory failure, uncontrolled infection, bleeding tendencies, tracheal stenosis and acute attack of bronchial asthma) were excluded from our study.

Methods: All patients included in the study were subjected to the following work-up:

- Full history taking.

- Clinical examination.
- Plain chest X-ray.

- CT Chest.

- Routine laboratory investigations.

- Coagulation profile.

- Arterial blood gases sample.

- Electrocardiogram (ECG).

- Vital signs including blood pressure, pulse, respiratory rate, temperature.

All samples was done by the currently available CP-EBUS in Kobbry Al-Kobba Military Hospital is an ultrasound puncture bronchoscope with a 7.5$\mathrm{MHz}$ convex transducer placed at the tip of a flexible bronchoscope (pentax).

\section{Statistical analysis:}

Data were revised for completeness and consistency. Accordingly, some questionnaires were excluded from the study and replaced by an equal number of other patients. Pre-coded data were entered and analyzed with the aid of Statistical Package of Social Science Software program (SPSS) version 22.

Mean, standard deviation, range, frequency and percentages were used as descriptive statistics. Chi square test and $t$-test were used according to type of variables analyzed.

The results were represented in tabular and diagrammatic forms then interpreted.

\section{Results}

The mean age of the patients participating in this study was $44.9 \pm 15.9$ and range from 17-73 years old. $17(56.7 \%)$ patients were male and 13 $(43.3 \%)$ were females. $16(53.3 \%)$ patients were smokers while the other $14(46.7 \%)$ are not. 2 patients $(6.7 \%)$ were diabetics, 1 (3.3) was hypertensive and $10(33.3 \%)$ patients were diabetic and hypertensive, while the rest $17(56.7 \%)$ were not having any comorbidities.

The most common complain presented to our outpatients clinic were cough in $27(90.0 \%)$, then Dyspnea in $26(86.9 \%)$, Expectoration in $(70.0 \%)$, Chest pain in $12(40.0 \%)$ and Hemoptysis in 5 $(16.7 \%)$ patients.

Regarding radiological findings among the patients in the study were $12(40.0 \%)$ of patients diagnosed as hilar \& mediastinal lymphadenopathy, $2(6.7 \%)$ of patients diagnosed as mediastinal lymphadenopathy, $3(10.0 \%)$ of patients were diagnosed as hilar lymphadenopathy, 10 (33.3\%) of patients were diagnosed as pulmonary lesions, 
$2(6.7 \%)$ of patients were diagnosed as pulmonary lesions with mediastinal lymphadenopathy, 1 (3.3\%) of patients were diagnosed as pulmonary lesions with mediastinal and hilar lymphadenopathy.

The Endobronchial ultrasound findings among the patients in the study were 10 patients $(33.3 \%)$ were having endobronchial mass lesions and 20 patients (66.7\%) were having Lymph Node Lesions.

The pathological findings among studied group were $13(43.3 \%)$ of patients diagnosed as malignant lesions and 17 (56.7\%) of patients diagnosed as benign lesions.

Final Diagnosis of the patients in the study was 2 cases $(6.7 \%)$ were having metastatic adenocarcinoma, 2 cases $(6.7 \%)$ were having large cell carcinoma, 14 cases (46.7\%) were having Sarcoidosis, 4 cases $(13.3 \%)$ were having small cell carcinoma, 2 cases $(6.7 \%)$ were having Non-small cell carcinoma, 3 cases $(10.0 \%)$ were having Non-Hodgkin lymphoma, 2 cases $(6.7 \%)$ were having Nonspecific granulomatous reaction, 2 cases $(6.7 \%)$ were having T.B. lymphadenitis.

The complication reported form the use of EBUS was minor hemorrhage in one case "3.3\%" and no other complications were reported in the rest of cases.

Also our results showed that there was a statistically significant relation between EBUS findings and pathological findings among studied group with a $p$-value $<0.001$.

We found that the sensitivity, specificity, PPV, NPV of EBUS guided TBNA in distinguishing benign from malignant lymph nodes and masses were $95.0 \%, 100.0 \%, 100.0 \%$ and $76.9 \%$, respectively.

Table (1): Demographic distribution of the patients.

\begin{tabular}{ll}
\hline Variable & Mean \pm SD \\
\hline Age: (years): & $44.9 \pm 15.9$ \\
Range & $17-73$ \\
Gender: & \\
Male & $17(56.7 \%)$ \\
Female & $13(43.3 \%)$ \\
Smoking Habits & \\
Smoker & $16(53.3 \%)$ \\
Non-Smoker & $14(46.7 \%)$ \\
Comotbidities & \\
Diabetic & $2(6.7 \%)$ \\
Hypertensive & $1(3.3 \%)$ \\
Diabetic and Hypertensives & $10(33.3 \%)$ \\
No Comorbidities & $17(56.7 \%)$ \\
\hline
\end{tabular}

Table (2): Relation between EBUS and pathological findings among studied group

\begin{tabular}{cccccc}
\hline Lymph & 17 & 3 & 20 & 19.615 & 0.000 \\
Node & $(85.0 \%)$ & $(15.0 \%)$ & $(100 \%)$ & $(\mathrm{S})$ \\
Mass & & 0 & 10 & 10 \\
& & $(0.0 \%)$ & $(100.0 \%)$ & $(33.3 \%)$ \\
\hline Total & & 17 & 13 & 30 \\
\hline
\end{tabular}

Comorbidities Distribution

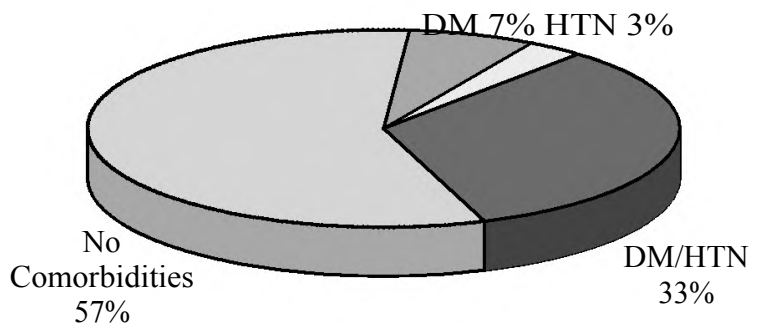

Fig. (1): Distribution of comorbidities among the patients in the study.

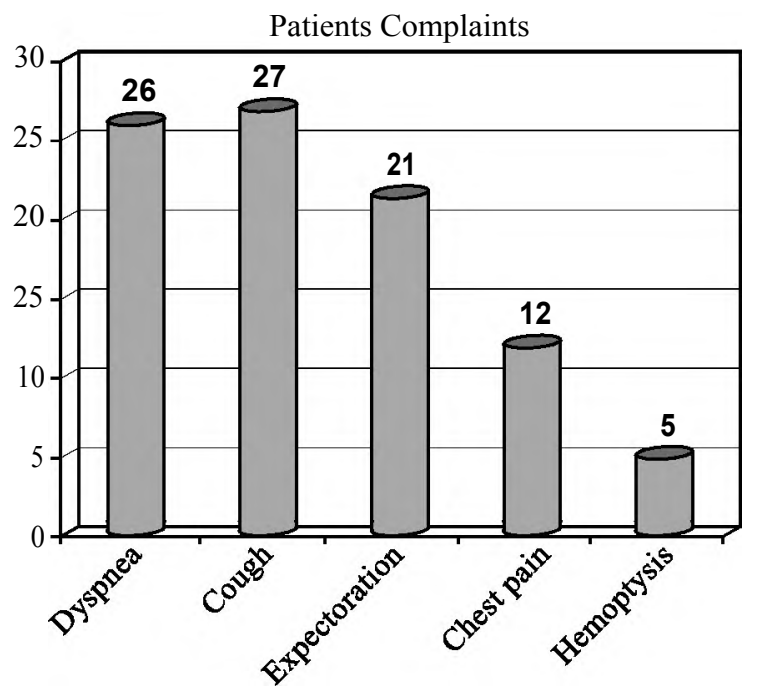

Fig. (2): Patients complaints in the study.

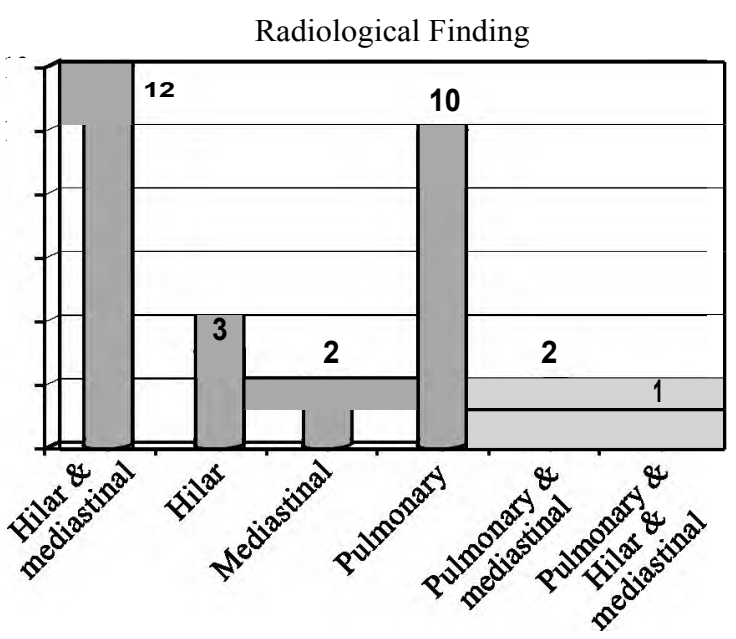

Fig. (3): Radiological finding of the patients in the study. 


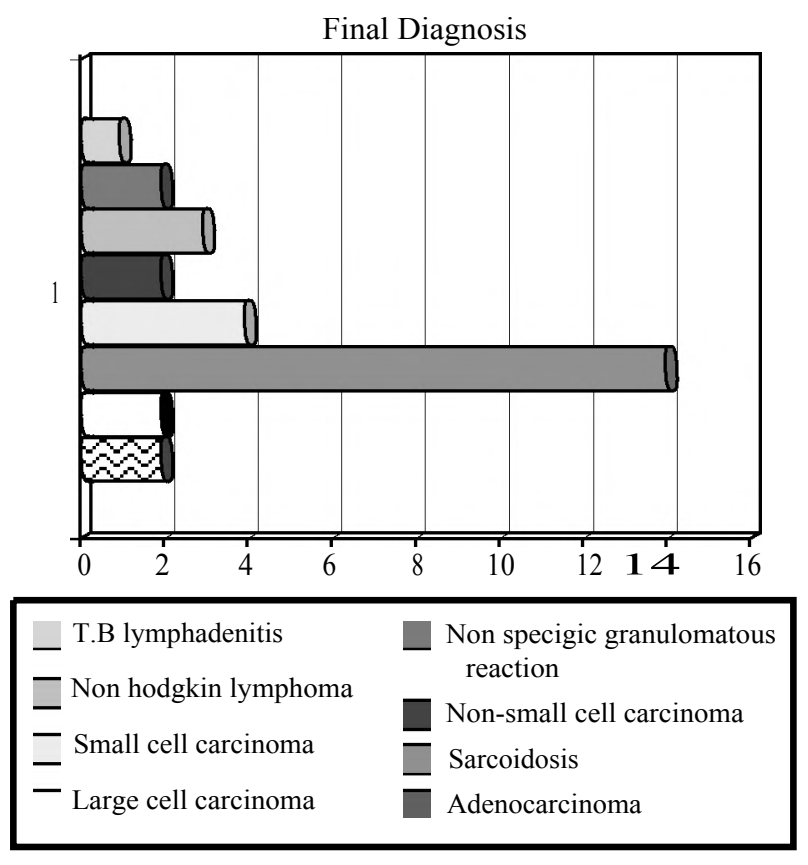

Fig. (4): Final diagnosis of the patients in the study.

\section{Discussion}

Early diagnosis and staging of pulmonary lesions are central to the treatment and survival of patients with suspected lung cancer, especially of those with suspected non-small cell lung cancer. Lung cancer accounts for the majority of mediastinal and hilar lymphadenopathies [11].

Intrathoracic lymph node enlargement is the most common finding in patients with malignancies. Intrathoracic lymph node metastases of extrapulmonary malignancies are variable but less common than lung cancer. Mediastinal metastases represent an advanced stage of lung cancer and have a poor prognosis. Up to $30 \%$ of extrathoracic malignancy cases could metastasize to the mediastinum [12] .

Available procedures for investigating intrathoracic lymph node enlargement include imaging techniques, mediastinoscopy (MS), open thoracic surgery and endoscopic ultrasound-guided fine needle aspiration (EUS-FNA). Magnetic resonance imaging (MRI), computed tomography (CT) and positron emission tomography (PET) are often regarded as insufficient for making a clinical decision because of the lack of a tissue diagnosis [13]. MS and thoracic surgery are standard methods for confirming undiagnosed mediastinal lymph nodes [13] . However, drawbacks to these techniques include their invasiveness, the need for clinical admission, the requirement of general anaesthesia and higher costs [14].
The primary role of EBUS-TBNA has been the diagnosis and staging of lung cancer, but its role is expanding to include diagnosis of early stage sarcoidosis, mediastinal or hilar lymphadenopathy, and other mediastinal lesions [14]

Specimens collected by Transbronchial needle aspiration "TBNA" were examined histopathologically and the collected data were statistically analyzed and showed that 13 patients had a malignant lesions in a percentage of $43.3 \%$. Two patients of those 13 patients were diagnosed as adenocarcinoma in a percentage of $15.4 \%$ " $6.7 \%$ of the whole patients in the study". Another 2 patients of the 13 patients diagnosed to have malignant lesion were diagnosed as large cell carcinoma in a percentage of $15.4 \%$ " $6.7 \%$ of the whole cases". Small cell carcinoma was diagnosed in 4 patients of the 13 patients with malignancy in a percentage of $30.8 \%$ " $13.3 \%$ of whole cases" while non-small cell carcinoma was presented in only 2 patients in percentage of $15.4 \%$ " $6.7 \%$ of whole cases". The rest of cases " 3 cases" with malignant lesion were diagnosed as non-Hodgkin lymphoma in a percentage of $23 \%$ " $10 \%$ of whole cases".

The other 17 patients were diagnosed by histopathology to have benign lesions in percentage of $56.7 \%$. Fourteen cases of those 17 patients were diagnosed as sarcoidosis in a percentage of $82.4 \%$ " $46.7 \%$ of whole cases", while non-specific granulomatous reaction was diagnosed in 2 patients of those 17 ones in a percentage of $11.8 \%$ " $6.7 \%$ of whole cases". Only one patient of those 17 patients diagnosed as T.B. lymphadenitis in a percentage of $5.8 \%$ " $3.3 \%$ of whole cases".

These results showed that EBUS-TBNA has a significant role in diagnosis of sarcoidosis " 14 cases $(82.4 \%)$ of cases with benign lesions and $(46.7 \%)$ of total cases".

These results goes in agreement with, the results of the study done by Navasakulpong et al., [15] in which 43 patients underwent 45 EBUS-TBNA procedures for suspected sarcoidosis. Non-necrotizing granulomatous inflammation was detected in EBUS-TBNA samples from 34/45 (76\%) procedures. The overall diagnostic yield increased to $36 / 45(80 \%)$ following a cytopathology review for this study. Needle gauge, number of lymph node stations sampled and number of needle passes were not associated with diagnostic yield. The yield of EBUS-TBNA increased significantly after the first 15 procedures performed for suspected sarcoidosis; the 2 additional cases diagnosed after the cytopathology review were part of this early experience. And concluded that "EBUS-TBNA is a valuable 
technique for the diagnosis of sarcoidosis when performed without ROSE.".

Also these results goes in harmony what was reported by Garwood, et al., [16] in there results that "Fifty consecutive patients who had been referred for EBUS-TBNA for suspected pulmonary sarcoidosis were included in the study EBUSTBNA demonstrated noncaseating granulomas without necrosis in 41 of 48 patients $(85 \%)$ with a final diagnosis of sarcoidosis. EBUS-TBNA, therefore, has a sensitivity of $85 \%$ for the primary diagnosis of pulmonary sarcoidosis". And concluded that "EBUS-TBNA is a high-yield, safe modality for diagnosing noncaseating, and epithelioid granulomas in patients with a high clinical suspicion for pulmonary sarcoidosis. EBUS-TBNA has many theoretical advantages over other diagnostic techniques in terms of diagnostic yield and morbidity, which we suspect will make it the diagnostic procedure of choice. As with all diagnostic approaches to sarcoidosis, a biopsy specimen showing granulomatous inflammation must be viewed in context with all of the clinical data.

As regard complications recorded during our study we found that there was no complications recorded in 29 patients in percentage of $96.7 \%$ while only patient has a minor complication "minor bleeding" in percentage of $3.3 \%$.

These results goes in harmony with Verma, et al., [17] who reported in there results that only Two patients of total thirty seven patients experienced complications. One developed pneumothorax requiring chest tube insertion and another patient developed moderate bleeding which resolved spontaneously. Both patients recovered from their complications uneventfully. And concluded that "EBUS-TBNA is an effective and safe method for tissue diagnosis of parenchymal lesions that lie centrally close to the airways".

These results goes against what was reported by Asano, et al., [18] in their nationwide survey that was conducted by the Japan Society for Respiratory Endoscopy (JSRE) on EBUS-TBNA current usage status and complications associated with its use. They do a questionnaire about EBUSTBNA performed between January 2011 and June 2012 was mailed to 520 JSRE-accredited facilities and Responses were obtained from 455 facilities $(87.5 \%)$. During the study period, EBUS-TBNA was performed in 7,345 cases in 210 facilities (46.2\%) using a convex probe ultrasound bronchoscope, for 6,836 mediastinal and hilar lesions and 275 lung parenchymal lesions. Ninety complications occurred in 32 facilities. The complication rate was $1.23 \%$ (95\% confidence interval, $0.97 \%$ $1.48 \%$ ), with hemorrhage being the most frequent complication (50 cases, $0.68 \%$ ). Infectious complications developed in 14 cases $(0.19 \%)$ (Mediastinitis, 7; pneumonia, 4; pericarditis, 1; cyst infection, 1; and sepsis, 1). Pneumothorax developed in 2 cases $(0.03 \%)$, one of which required tube drainage. Regarding the outcome of the cases with complications, prolonged hospitalization was observed in 14 cases, life-threatening conditions in 4 , and death in 1 (severe cerebral infarction) (mortality rate, $70.01 \%$ ). Breakage of the ultrasound bronchoscope occurred in 98 cases $(1.33 \%)$ in 67 facilities $(31.9 \%)$, and that of the puncture needle in 15 cases $(0.20 \%)$ in 8 facilities $(3.8 \%)$. And at the end of their study they concluded that "Although the complication rate associated with EBUS-TBNA was found to be low, severe complications, including infectious complications, were observed, and the incidence of device breakage was high. Since the use of EBUS-TBNA is rapidly expanding in Japan, an educational program for its safe performance should be immediately established".

There was statistical significant difference between the EBUS findings and the pathological finding " $p$-value $<0.01$ ". There was no mass lesion detect as benign lesion, all of them "10 mass lesion" was found to be malignant in a percentage of $100 \%$. While the lymph node lesions "20 LN lesions" were found to be 17 diagnosed as benign in a percentage of $85.0 \%$ while the rest of them were found to be malignant lesion in percentage of $15 \%$. The sensitivity, specificity, PPV, NPV of EBUS guided TBNA in distinguishing benign from malignant lymph nodes and masses were $95.0 \%$, $100.0 \%, 100.0 \%$ and $76.9 \%$, respectively.

These results goes in agreement with FernándezBussy, et al., [19] who reported in their prospective study The EBUS-TBNA method showed a sensitivity of $91.17 \%$, a specificity of $100.0 \%$, and a negative predictive value of $92.9 \%$ and from 354 mediastinal lymph node biopsies obtained a definitive diagnosis was established by EBUS-TBNA in 164 cases.

\section{Conclusion:}

Endobronchial ultrasound guided transbronchial fine needle aspiration EBUS-TBNA is the procedure of choice for staging of lung cancers and for the investigation of unexplained mediastinal lymphadenopathy and masses. EBUS guided TBNA is an accurate, cost effective and minimally invasive procedure and if successfully performed, TBNA may spare patients additional, more invasive procedures or surgery. 


\section{References}

1- SCHUHMANN M., EBERHARDT R. and HERTH F.J.: Endobronchial Ultrasound for Peripheral Lesions: A ReviewEndosc Ultrasound. Jan-Mar., 2 (1): 3-6, 2013.

2- BALAMUGESH T. and HERTH FJ.: Endobronchial ultrasound: A new innovation in bronchoscopy. Lung India. Jan-Mar., 26 (1): 17-21, 2009.

3- HATA Y., SAKAMOTO S., OTSUKA H., et al.: EBUSTBNA-related complications in a patient with tuberculous lymphadenopathy. Intern. Med., 52 (22): 2553-9, 2013.

4- CHEN C.H., LIAO W.C., et al.: Endobronchial Ultrasound Changed the World of Lung Cancer Patients: A 11-Year Institutional Experience. PLoS. One, 10 (11): e0142336, 2015.

5- YASUFUKU K., NAKAJIMA T., FUJIWARA T., YOSHINO I. and KESHAVJEE S.: Utility of endobronchial ultrasound-guided transbronchial needle aspiration in the diagnosis of mediastinal masses of unknown etiology. Ann Thorac Surg. Mar., 91 (3): 831-6, 2011.

6- KAUR G., DHAMIJA A., AUGUSTINE J., BAKSHI P. and VERMA K.: Can cytomorphology of granulomas distinguish sarcoidosis from tuberculosis? Retrospective study of endobronchial ultrasound guided transbronchial needle aspirate of 49 granulomatous lymph nodes. Cytojournal. Sep., 27. $10: 19,2013$.

7- STEINFORT D.P., KHOR Y.H., MANSER R.L. and IRVING L.B.: Radial probe endobronchial ultrasound for the diagnosis of peripheral lung cancer: Systematic review and meta-analysis. Eur. Respir. J. Apr., 37 (4): 902-10, 2011.

8- HERTH F.J., EBERHARDT R., BECKER H.D. and ERNST A.: Endobronchial ultrasound-guided transbronchial lung biopsy in fluoroscopically invisible solitary pulmonary nodules: A prospective trial. Chest. Jan., 129 (1): 147-50, 2006.

9- RIVERA M.P., MEHTA A.C. and WAHIDI M.M.: Establishing the diagnosis of lung cancer: Diagnosis and management of lung cancer, ed: American College of Chest Physicians evidence-based clinical practice guidelines. Chest., 143: e142S, 2013.

10- YANG B., LI F., SHI W., LIU H., SUN S., et al.: Endobronchial ultrasound-guided transbronchial needle biopsy for the diagnosis of intrathoracic lymph node metastases from extrathoracic malignancies: A meta-analysis and systematic review. Respirology. Aug., 19 (6): 834-41, 2014.

11- De LEYN P., LARDINOIS D., VAN SCHIL P.E., RAMIPORTA R., et al.: ESTS guidelines for preoperative lymph node staging for non-small cell lung cancer. Eur. J. Cardiothorac. Surg., 32: 1-8, 2007.

12- HAMMOUD Z.T., ANDERSON R.C., MEYERS B.F., GUTHRIE T.J., et al.: The current role of mediastinoscopy in the evaluation of thoracic disease. J. Thorac. Cardiovasc. Surg., 118: 894-9, 1999.

13- CASTELAO NAVAL J., IZQUIERDO ALONSO J.L., GALLARDO CARRASCO J., et al.: Clinical utility and economic impact of conventional transbronchial needle aspiration of mediastinal lymphadenopathies in bronchogenic carcinoma. Arch. Bronconeumol., 49: 41-6, 2013.

14- TRISOLINI R., LAZZARI AGLI L., TINELLI C., et al.: Endobronchial ultrasoundguided transbronchial needle aspiration for diagnosis of sarcoidosis in clinically unselected study populations. Respirology, 20: 226e234, 2015.

15- NAVASAKULPONG A., AUGER M. and GONZALEZ A.V.: Yield of EBUS-TBNA for the diagnosis of sarcoidosis: impact of operator and cytopathologist experience. BMJ. Open. Respir. Res. Aug., 9; 3 (1): e000144, 2016.

16- GARWOOD S., JUDSON M.A., SILVESTRI G., et al.: Endobronchial ultrasound for the diagnosis of pulmonary sarcoidosis. Chest. Oct., 132 (4): 1298-304, 2007.

17- VERMA A., JEON K., KOH W.J., SUH G.Y., CHUNG M.P., et al.: Endobronchial ultrasound-guided transbronchial needle aspiration for the diagnosis of central lung parenchymal lesions. Yonsei. Med. J. May, 1; 54 (3): 672 $8,2013$.

18- ASANO F., AOE M., OHSAKI Y., OKADA Y., et al.: Complications associated with endobronchial ultrasoundguided transbronchial needle aspiration: A nationwide survey by the Japan Society for Respiratory Endoscopy. Respir Res. May, 10 (14): 50, 2013.

19- FERNÁNDEZ-BUSSY S., LABARCA G., CANALS S., CAVIEDES I., et al.: Diagnostic yield of endobronchial ultrasound-guided transbronchial needle aspiration for mediastinal staging in lung cancer. J. Bras. Pneumol., May-Jun., 41 (3): 219-24, 2015. 


\section{دور المنظار الشعبى تحت توجيه الموجات فوق الصوتية المروفية

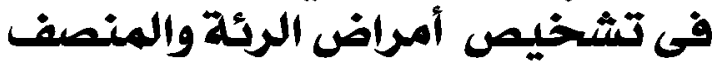

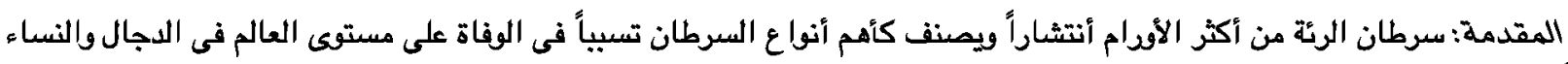

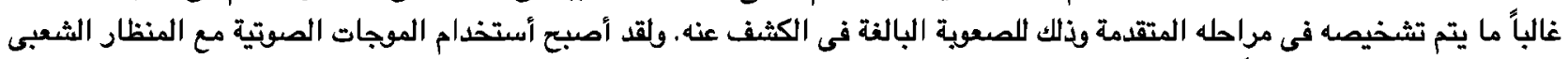

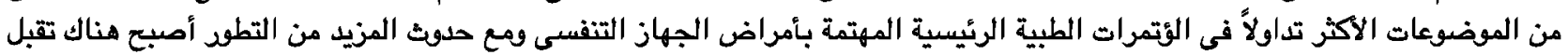

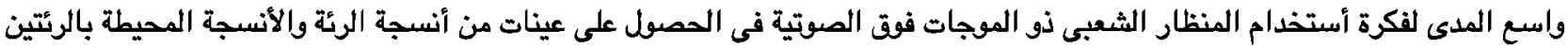

والمجرى التنفسى بأستخدام أبرة خاصة.

الهدف من البحث: تقييم لود أستخلاص العينات بواسطة الأبرة الجراحية مع المنظار الشعبى المزفو بالموجات فوق الصوتية في تشخيص أودام الجهاز التنفسى والمنصف كأداة أقل تدخلاً وأكثر دقة وآماناً.

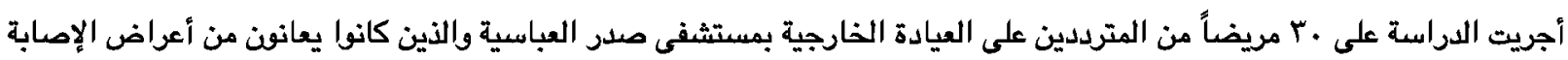

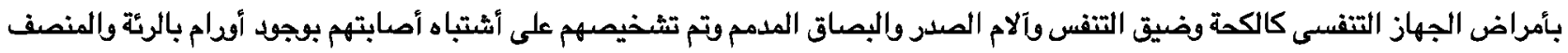

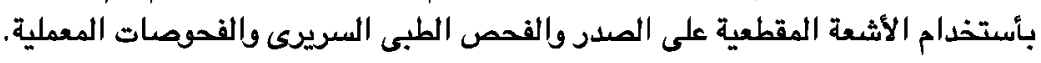

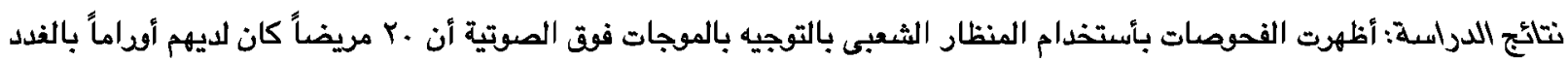

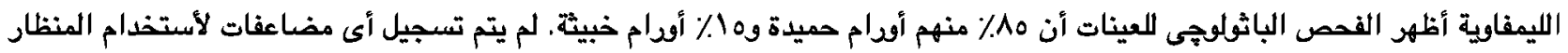

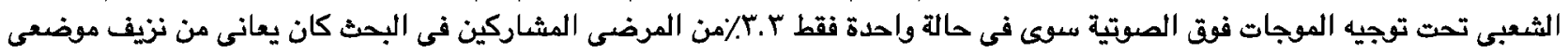

الخلاصة: أثبت البحث أن استخدام المنظار الشعبى تحت توجيه الموجات فوق الصوتية في الصصول على عينات من أودام الغدد الليمفاوية

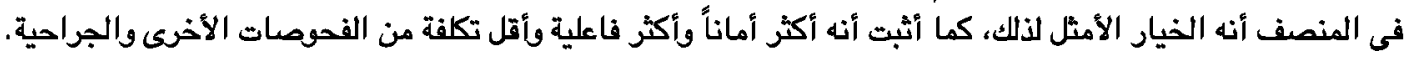

